\title{
La localidad de Daimiel (Ciudad Real): una apuesta por el patrimonio a través de la investigación, conservación y difusión
}

\author{
Miguel Torres Mas $^{\mathrm{a}}$
}

${ }^{a}$ Ayuntamiento de Daimiel/Motilla del Azuer, Luis Ruiz Valdepeñas nº 6, 13250, Daimiel, motilladelazuer@aytodaimiel.es

\begin{abstract}
Resumen
La localidad de Daimiel (Castilla-La Mancha/España) cuenta con un patrimonio excepcional representado en espacios naturales como Las Tablas de Daimiel o Navaseca, o desde una perspectiva cultural contando con enclaves como la Motilla del Azuer, Venta de Borondo, las Caleras o Puente Viejo.

Los trabajos en torno al estudio, conservación y difusión de estos bienes proporcionan amplias posibilidades desde el punto de vista económico, social y cultural. Por esta razón, el Ayuntamiento de Daimiel, dentro de la misión de tutela que debe implicar a una institución pública, ha impulsado una línea estratégica para la gestión de estos recursos. Asimismo, debido a las características y particularidades de estos vestigios, el modelo generado necesita del planteamiento de una experiencia que sea sostenible, viable y eficaz.

A través de estas páginas presentamos los proyectos que se han efectuado en los últimos años en una serie de conjuntos arqueológicos de esta localidad. Las labores emprendidas están significando un activo provechoso para la dinamización y el desarrollo de este territorio, así como para el aprovechamiento y promoción de este patrimonio.
\end{abstract}

Palabras clave: patrimonio, gestión, tutela, valorización, Motilla del Azuer, Venta de Borondo.

\begin{abstract}
The town of Daimiel (Castilla-La Mancha/Spain), has an exceptional heritage represented in natural sites such us Las Tablas de Daimiel or Navaseca, or from a cultural perspective with sites such as Motilla del Azuer, Venta de Borondo, Las Caleras or Puente Viejo.

The work around the study, conservation and diffusion of this heritage provides wide possibilities from an economic, social and cultural point of view. For this reason, the town hall of Daimiel, within the mission of guardianship that involves a public institution, has decided to promote a strategic line around the management of these resources. In addition, due to the characteristics of these vestiges, the models generated need approaches that are precise, suitable and viable for the reality of each of these elements.
\end{abstract}

Through these pages we present the projects that have been carried out in recent years in a series of archeological assets. The work that has been taken, is meaning a beneficial field for the revitalization and development of this territory, as well as for the use and promotion of this heritage.

Keywords: heritage, management, tutelage, valorization, Motilla del Azuer, Venta de Borondo. 


\section{Introducción}

La localidad de Daimiel cuenta con unos recursos patrimoniales excepcionales, tanto desde el punto de vista natural, sobre todo representado en el Parque Nacional de Las Tablas de Daimiel, como cultural, con entidades como el yacimiento prehistórico de la Edad del Bronce de la Motilla del Azuer o la Venta de Borondo, una de las últimas ventas de llanura de cronología bajomedieval-moderna conservadas. Además, en los últimos años se están ejecutando una serie de acciones que han permitido valorizar otros bienes, tanto naturales como culturales, entre los que destacan la laguna de Navaseca, las Caleras o el Puente Viejo, resultando exponentes muy ilustrativos de la relevancia de este legado en la zona.

Las riquezas y posibilidades que atesoran estos elementos constituyen activos para el desarrollo de un territorio, con una incidencia favorable en sectores como el cultural, social o económico. A este respecto, su gestión simboliza un campo con amplias posibilidades desde múltiples enfoques. Entre otras consideraciones, una explotación eficaz proporciona un estímulo económico, ya que es origen de una fuente de ingresos, tanto directos como indirectos, puestos de trabajo cualificados y está asociado al consumo de unos servicios que repercuten en beneficio del tejido productivo de una región. En los mismos términos, los rendimientos obtenidos resultan beneficiosos para los propios recursos, al incorporar un efecto "retorno" que compensa los esfuerzos realizados en los mismos (Martínez, 2014). Por tanto, la apuesta por una administración precisa de estos vestigios supone un motor de dinamización para una población, incluso con una mayor incidencia para aquellas áreas que presentan dificultades desde parámetros económicos y financieros.

En virtud de esta realidad, el Ayuntamiento de Daimiel ha decidido impulsar una línea estratégica para establecer una organización idónea de sus principales elementos patrimoniales. Esta experiencia se ha diseñado a través de un paradigma que tiene en cuenta el estudio, conservación y difusión de los mismos, en el que estos tres principios se sitúan en el mismo nivel y a la misma altura de la toma de decisiones (López-Menchero, 2012). Es decir, este sistema busca aprovechar todas las fortalezas y valores que ostenta per se este patrimonio. No obstante, es preciso tener en consideración que estas manifestaciones por definición tienen unos planteamientos, postulados y problemáticas con ciertas particularidades. De forma específica, se caracterizan por poseer unas coordenadas espaciales y temporales que los convierten en únicos. Esta singularidad significa un polo de atracción intrínseco, asociado a un emplazamiento físico concreto, pero de igual manera implica una limitación evidente, ya que su disfrute está asociado a unos bienes que por naturaleza son frágiles, no renovables e irrepetibles. Por esta razón, ha de trazarse modelos que sean sostenibles y respetuosos con ese legado, esbozando modelos viables y adecuados dentro del contexto en el que se enmarcan, sin que ello exponga un perjuicio para su preservación efectiva.

A continuación presentamos detenidamente la gestión que se está emprendiendo en los últimos años en diferentes enclaves patrimoniales de la localidad de Daimiel, cuyos esfuerzos en una valorización integral están permitiendo avanzar en su interpretación y proyección.

\section{La gestión del patrimonio cultural en Daimiel}

Como se ha comentado en el punto introductorio, para optimizar un planteamiento relativo a la tutela del patrimonio es imprescindible la adopción de un programa determinado de acciones que faciliten su interpretación, mantenimiento y explotación. Para ello, en este caso ha resultado pertinente fortalecer aquellos aspectos que particularizan los potenciales recursos dentro de una configuración que garantice su seguridad estructural y su integridad patrimonial. Igualmente, es conveniente la incorporación de diferentes medidas preventivas, que en todo momento faciliten la conservación futura de sus conjuntos ante la amenaza continua de agentes erosivos externos, como los advertidos en este medio físico (Angulo, 2018).

\subsection{La Motilla del Azuer}

La Motilla del Azuer resulta un caso paradigmático dentro del patrimonio de la localidad. Representa el yacimiento mejor conocido dentro de la tipología "motillas", definidas en el horizonte de la Edad del Bronce de La Mancha (22001350 a.n.e.). Las campañas arqueológicas realizadas, desde que comenzaron en el año 1974, han permitido identificar 
en su interior un recinto fortificado a través de tres líneas murarias concéntricas en torno a una torre central, como se puede observar en la figura 1. Esta fortificación sirvió para la defensa y control de recursos críticos para estas gentes, como el almacenamiento de grano, el estabulamiento ocasional del ganado, áreas productivas de diversa índole o habitaciones para depositar productos elaborados u objetos artesanales (Nájera y Molina, 2004). Pero, sobre todo, permitió el abastecimiento de agua a través de un monumental pozo, punto icónico dentro de todo el monumento, que facilitó el acceso a este bien durante la ocupación del emplazamiento. Mientras, al exterior de esta fortificación se situaba el área del hábitat (Nájera et al., 2012).

Debido a su representatividad, en el año 2012 el Ayuntamiento de Daimiel, tras un acuerdo con la Junta de Comunidades de Castilla-La Mancha, propietaria de este sitio arqueológico, decidió iniciar la explotación para desarrollar visitas en su perímetro. La pretensión fue la de aprovechar el interés que suscitaba este complejo con el diseño de trayectos guiados que repercutieran favorablemente en el entorno. Para llevar a cabo este propósito, tuvo que realizarse inicialmente el acondicionamiento exhaustivo de todo su recinto, exponiendo todas las estructuras existentes sin que ello constituyera un riesgo para la construcción prehistórica (Torres, 2015).

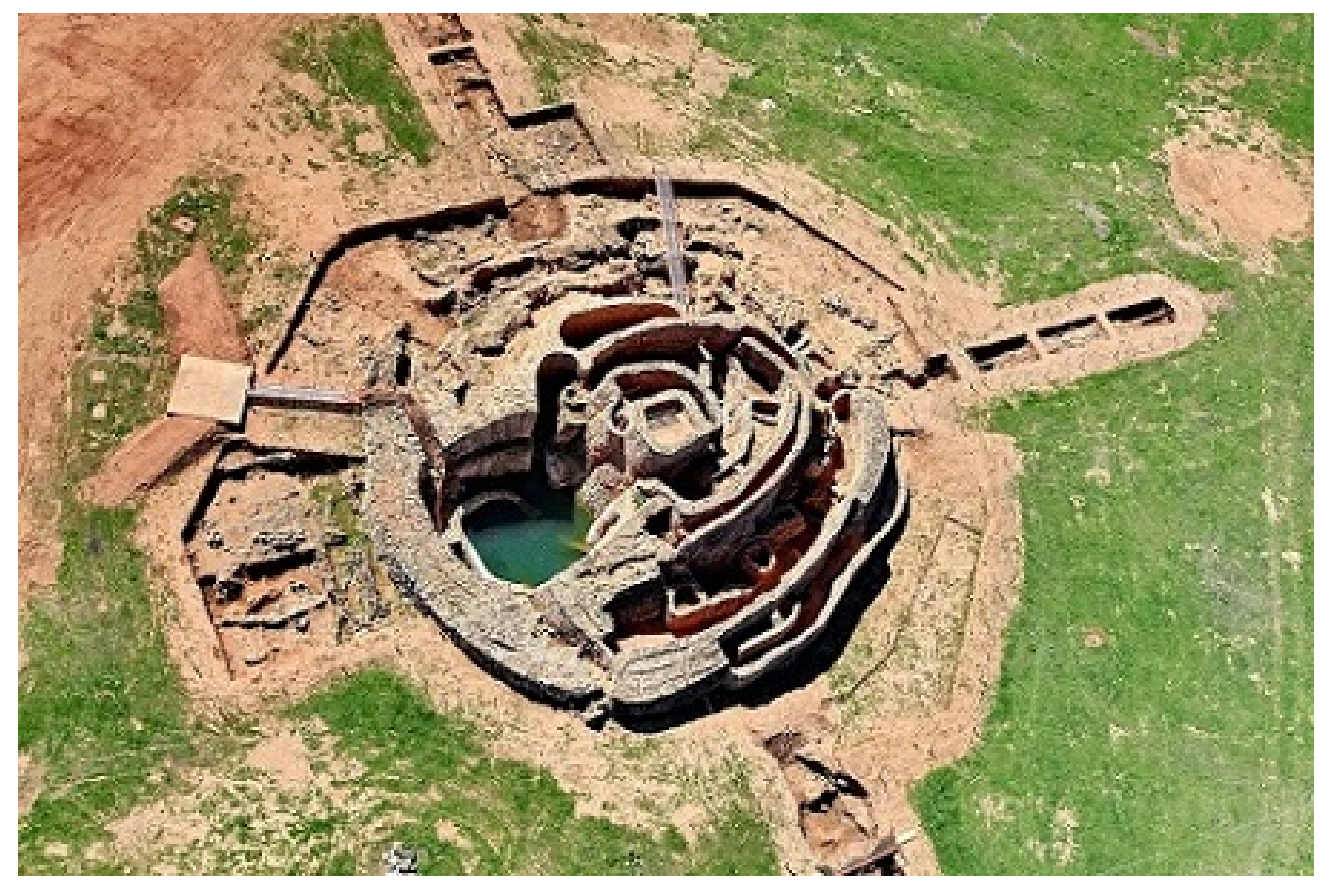

Fig. 1 Motilla del Azuer

El modelo planteado ha sido generado ex professo, a través de un equipo de trabajo de diferentes áreas dentro del propio Ayuntamiento, como los Departamentos de Turismo y Arqueología y Patrimonio, el Museo Comarcal y los propios responsables políticos de esta institución. El objetivo fue el de ofrecer unas valoraciones y enfoques heterogéneos y complementarios, para lograr una experiencia que fuera positiva y precisa.

En este sentido, una de las premisas establecidas fue que las visitas debían ser controladas, organizadas y guiadas. Para lo cual, se estimó que la entrada debía adquirirse de manera anticipada, bien físicamente en el Museo Comarcal de Daimiel o en la página web www.motilladelazuer.es. Igualmente, las rutas establecidas se adaptan al tipo de público potencial, planteando las categorías de modalidad individual o en grupo, en virtud del tipo de usuario registrado. Se trata de proporcionar una oferta abierta a diferentes necesidades y precios.

Con respecto a las visitas, éstas comienzan en el Museo Comarcal que de manera previa introduce al visitante en el contexto de la Motilla del Azuer. A través de dispositivos museográficos heterogéneos permiten ofrecer una análisis preliminar y global sobre esta fase crono-cultural. Una vez completada esta introducción, los visitantes son trasladados hacia el propio monumento, para efectuar el itinerario guiado por su interior. Concluido el recorrido, los usuarios vuelven otra vez a Daimiel, lo que supone una oportunidad para dar a conocer los activos potenciales de la ciudad. 
Esta experiencia se está efectuando de manera permanente desde su apertura en junio de 2014, y, en líneas generales, está resultando muy satisfactoria tanto para los visitantes, que señalan una alta puntuación sobre los servicios ofrecidos, como para la población de Daimiel, puesto que evidencia una ocasión para la promoción de su tejido productivo, ya que son más de 45.000 personas las que han visitado el yacimiento ${ }^{1}$.

Asimismo, en la Motilla del Azuer se han venido programando eventos desde una oferta cultural más amplia. Entre ellas se pueden situar la realización de un concierto en 2017 a cargo del artista local Ricardo Fernández del Moral, que tuvo como telón de fondo la propia fortificación del Bronce, el funcionamiento de rutas senderistas hacia el monumento o una iniciativa didáctica con los centros educativos de la localidad, por la cual conocen de primera mano este lugar tan próximo a su residencia.

\subsection{La Venta de Borondo}

Este inmueble es uno de los últimos ejemplos conservados de la tipología de ventas de llanura que funcionaron en esta región desde época bajomedieval-moderna. Fueron unos establecimientos concebidos para el hospedaje, dentro de las diferentes rutas de comunicación que vertebraron la Península Ibérica durante varias centurias. Además, en sus componentes, como se percibe en la figura 2, son advertidas características propias de la arquitectura vernácula de esta zona (Cejudo, 2013). Por esta razón, se trata de una manifestación singular que se sitúa dentro de los límites del municipio de Daimiel.

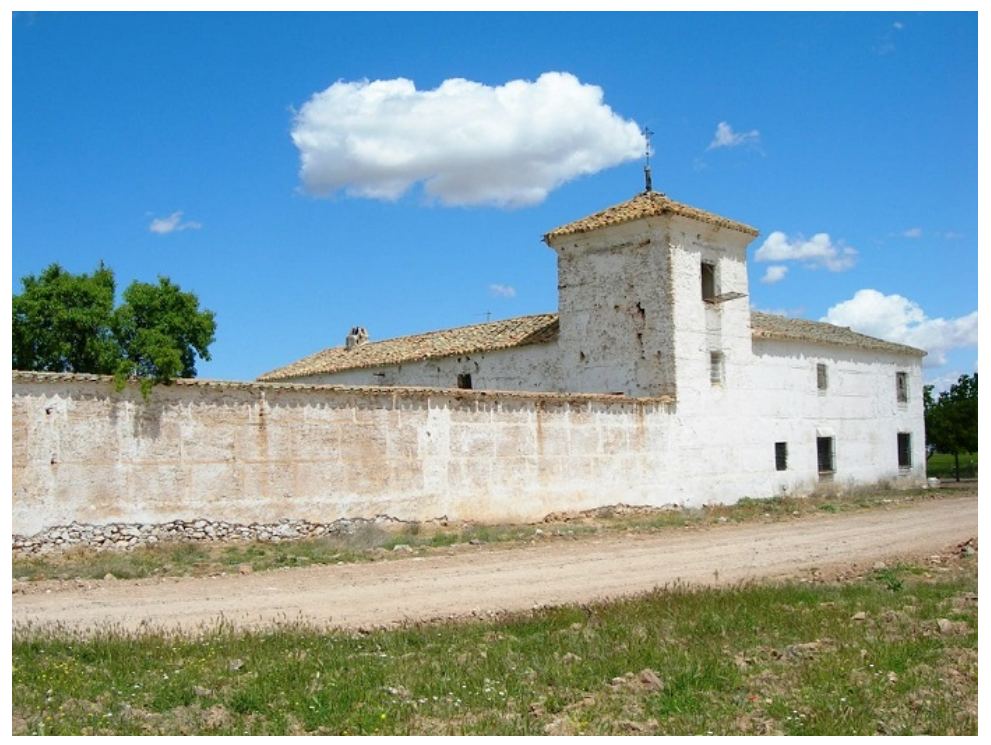

Fig. 2 Venta de Borondo

Tipológicamente se encuentra articulada por un recinto principal de planta rectangular de dos alturas, patio interior y torreón en la esquina suroeste, que constituye el referente icónico del monumento. La entrada, situada en la fachada principal este permite llegar al patio central, que cumplimentó una función preferencial para la distribución de los espacios. En torno al mismo se destinaron en la planta baja habitaciones usadas como cocinas, cuadras o almacenes, mientras que en el piso superior fue aprovechado con dormitorios y cámaras.

Anexas a la edificación, hacia el norte y el oeste, fueron erigidas una serie de infraestructuras con una clara vinculación agropecuaria. Estuvieron planteadas a partir de dos grandes patios, en los que se establecieron cuadras, corrales, almacenes y aposentos para aquellos trabajadores vinculados con estas faenas.

Pese al gran valor y singularidad que atesora, no había sido objeto de ningún tipo de actuación arqueológica hasta el año 2017. En esta fecha se ejecutaron labores de limpieza, desbrozado y vallado perimetral de ciertos puntos de riesgo de colapso. A pesar de que era evidente su mal estado de manera previa, esta campaña permitió advertir el daño que

${ }^{1}$ Datos Oficina de Turismo de Daimiel. 
presentaban ciertas partes, con la documentación de lesiones especialmente notorias en sectores como la torre, la nave oeste y la gran mayoría de las cubiertas. Ante esta situación, en 2018 se efectuó una intervención con el propósito de detener su degradación y permitir su valorización. Stricto sensu, el proyecto permitió la rehabilitación de la torre, un tramo de la fachada exterior de la nave oeste y sectores de las cubiertas meridional y occidental. Las operaciones trataron de salvaguardar la configuración original, consolidando aquellas alteraciones manifestadas sin modificar o alterar su fisonomía.

De manera análoga, se están llevando iniciativas para avanzar en su interpretación y en la aplicación de nuevas tecnologías. Por ejemplo, en 2019 se efectuó una digitalización integral de todo el inmueble. Este análisis ha generado un modelo digital del espacio que conforma la venta, visible a través de la plataforma SketchFab, que cuenta con una amplia accesiblidad, una excelente resolución e incorpora información de sustancial utilidad para cualquier tipo de usuario.

La trascendencia de la Venta originó que en el año 2017 se constituyera la asociación "A.C. Venta de Borondo y Patrimonio Manchego", que tiene entre sus objetivos fundamentales luchar por la salvaguarda de este bien ${ }^{2}$. Gracias al empeño de este colectivo se ha podido detener el deterioro del inmueble, así como adoptar medidas preventivas que favorezcan su perdurabilidad en el tiempo. También viene desarrollando actividades para su difusión, como la organización de visitas por su interior, la celebración del Día del Libro con la lectura del Quijote en su perímetro o programas con agrupaciones culturales o centros educativos.

\subsection{Las Caleras}

Las "caleras" fueron unos dispositivos que sirvieron para la transformación de la piedra caliza en cal, a través de unos característicos hornos empleados en la combustión (Fig. 3). Fue una actividad representativa en la localidad, puesto que su funcionamiento ocupó a un número importante de personas. Habitualmente se instalaron en grupos, aunque su explotación se configuró de forma individual por una familia distinta.

Su emplazamiento obedeció a criterios estratégicos, situándose en las proximidades de áreas fluviales y vías pecuarias. Esta ubicación respondía a la ventaja que suponía su cercanía al abastecimiento de recursos prioritarios para este proceso. Por un lado, la obtención de material combustible a través de plantas como masiegas, eneas o carrizos. Son especies con un alto poder calorífico y que se encuentran extendidas en lagunas y cursos fluviales. Mientras, su disposición en ámbitos públicos, como representaban los caminos pecuarios, fue más viable que en terrenos de propiedad privada.

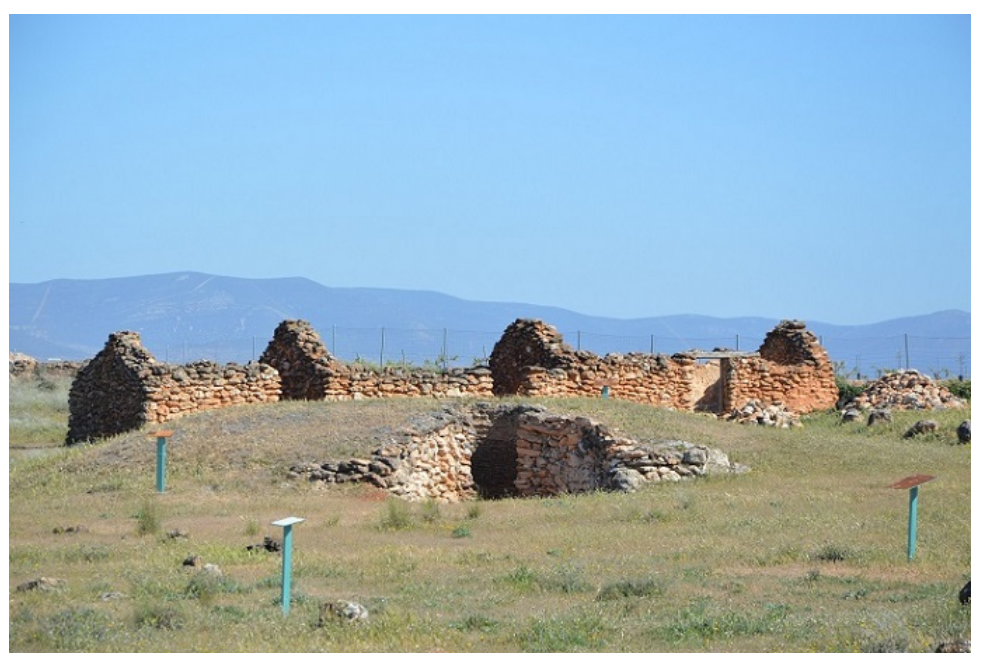

Fig. 3 Calera en el paraje las Salinas

\footnotetext{
${ }^{2}$ En virtud de un acuerdo establecido, en la actualidad los propietarios siguen siendo los herededos legítimos, aunque la asociación se encarga de su gestión y conservación.
} 
Los hornos presentaban una sección circular, de unos $2 \mathrm{~m}$ de diámetro por $3 \mathrm{~m}$ de altura, erigidos con mampostería de piedra caliza y revestimiento de ladrillo macizo. Al exterior contaron con un refuerzo de áridos, tierras y cenizas resultantes de las hornadas, dando el aspecto final con el que son reconocibles en el paisaje. Su interior estaba diferenciado por dos sectores. Un tramo inferior excavado en el suelo, conocido como "caldera", para aprovechar el carácter térmico que evitaba pérdidas de calor. Dentro de esta caldera se iban depositando a la leña por una abertura situada entre dos piedras verticales y una horizontal a modo de dintel. Sobre la cota de rasante del suelo se levantaba la "calera" propiamente dicha, donde se iban colocando las piedras a utilizar en el propio proceso (Fernández-Infantes, 2017). Cercanos a estos dispositivos fueron construidas una serie de viviendas donde se desarolló la vida de las gentes vinculadas con esta profesión. En líneas generales, estos inmuebles comparten analogías con la arquitectura rural tradicional de la comarca (Jérez, 2015).

La desaparición de esta industria durante el último tercio del siglo XX implicó el abandono de esta práctica, situación que afectó a estos dispositivos, con la pérdida de sus construcciones vinculadas. Ante esta situación, en el año 2007, la Asociación Ecologistas Manchegos de Daimiel decidió promover labores para la recuperación de unas 15 caleras (Fernández-Infantes, 2013), pero no logró una continuidad en el tiempo. En el año 2016 el Ayuntamiento de Daimiel emprendió una serie de campañas para la valorización de estos bienes, tareas que se han mantenido hasta la actualidad. Grosso modo, los proyectos emprendidos han tratado de acondicionar, preservar y poner en valor las infraestructuras asociadas. Estas iniciativas se han compaginado con actividades para dar a conocer estos elementos a la sociedad local. Así, se vienen organizando itinerarios de senderismo o visitas con diferentes agrupaciones y colectivos de la provincia. Los trabajos en las caleras también fueron los protagonistas de las IV jornadas de historia local ${ }^{3}$.

\subsection{Puente Viejo del Azuer}

El "Puente Viejo del Azuer" es un monumento de gran simbolismo para el municipio, gracias en buena medida a su cercanía al casco urbano, ya que se localiza a unos $500 \mathrm{~m}$ hacia el norte. Corresponde con una edificación levantada sobre el río Azuer. Como se distingue en la figura 4 está dispuesta por tres arcos de medio punto ejecutados en mampostería y sillería de piedra caliza sin concertar. Se sitúa dentro del itineario del camino localmente conocido como "Carril del Puente".

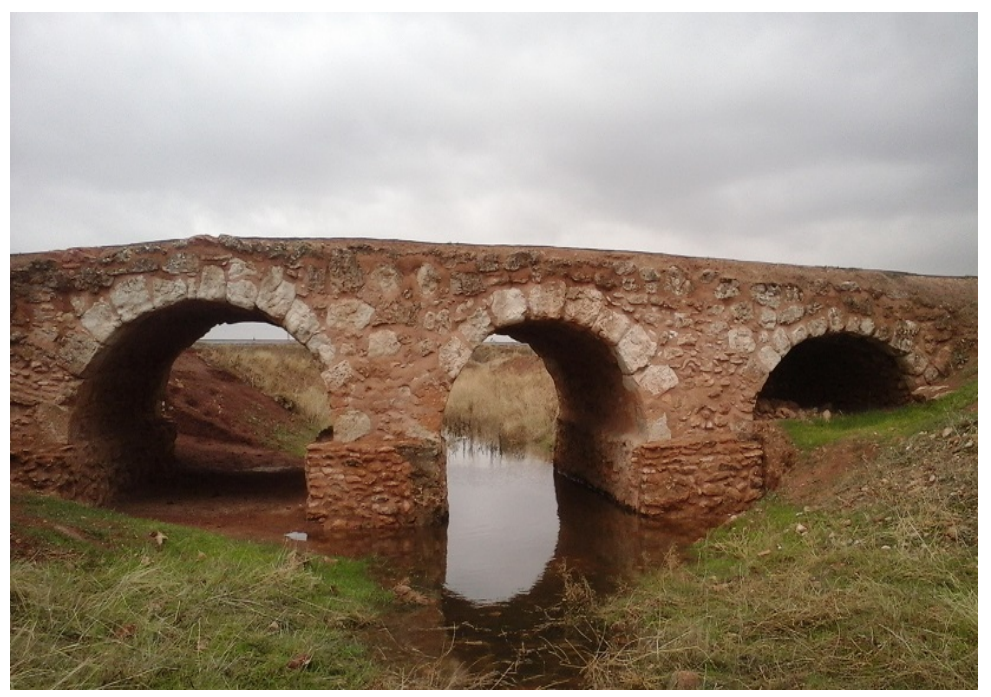

Fig. 4 Puente Viejo del Azuer

A pesar del reconocimiento que cuenta para la mayor parte de la población, el desarrollo de acciones de metodología arqueológica en su interior ha sido relativamente recientes, comenzando concretamente en el año 2017. Antes de iniciar estas operaciones era evidente el mal estado de conservación que presentaba, de tal forma que en el 2011 llegó a interrumpirse sine die el tránsito de vehículos motorizados por su superficie.

\footnotetext{
${ }^{3}$ El cartel, la comunicación inaugural y la portada de las actas de las IV Jornadas de Historia de Daimiel estuvieron dedicados a los trabajos desarrollados en las caleras.
} 
Debido a esta situación el Ayuntamiento de Daimiel decidió promover un proyecto integral que permitiera desarrollar un análisis exhaustivo sobre esta infraestructura, así como la realización de distintas labores que facilitaran su interpetación y la rehabilitación de sus paramentos. A este respecto, apenas se tenían datos históricos sobre la misma, por lo que la investigación fue enfocada también para obtener referencias sobre su cronología ${ }^{4}$.

De manera preliminar, se efectuó la limpieza de todo su contorno, retirando residuos orgánicos y la vegetación saliente en su superficie. Posteriormente, se procedió a la excavación arqueológica de dos sondeos en los sectores noreste y sureste. Los resultados ofrecieron observaciones muy valiosas. Así, se pudo documentar la existencia de una capa de rodadura formada por piedras calizas de pequeño tamaño trabadas con tierra apisonada, que había sido sepultada por niveles posteriores. Igualmente, fue registrada la existencia de un muro perpendicular al puente que sirvió para canalizar las aguas hacia el interior de los ojos. Además, esta campaña, así como la de 2018, permitió la consolidación de determinadas componentes. Concretamente, estos trabajos se extendieron a los cuatros tajamares definidos, el interior del intradrós de los ojos 2 y 3 , el muro localizado en los sondeos, los frentes sureste y noreste, o pequeños trozos de un enlucido de cal que revistió originalmente el exterior de los lienzos murarios.

Las actuaciones arqueológicas sobre Puente Viejo vienen motivas por el interés del Ayuntamiento de Daimiel por estudiar, preservar y valorizar un elemento patrimonial emblemático dentro de su término. Las acciones emprendidas han permitido garantizar su uso y disfrute, razón por la cual esta edificación se ha incluido en programas de difusión, como rutas de senderismo que transitan por su espacio. Asimismo, son numerosos los daimieleños que de forma diaria, como actividad ociosa, transitan hacia este recurso.

\section{Conclusiones: posibilidades, proyecciones y retos del patrimonio en Daimiel}

Las labores de investigación, rehabilitación y divulgación emprendidas en una serie de bienes emplazados en el término municipal de Daimiel han permitido definir un rico legado patrimonial en sus límites, que en virtud de sus características cuenta con múltiples posibilidades en su proyección. Por su significado poseen valores y símbolos que los convierten en únicos, singulares y excepcionales. Se trata de enclaves como la Motilla del Azuer, la Venta de Borondo, las Caleras o el Puente Viejo, que junto con el Parque Nacional de Las Tablas y la laguna de Navaseca referencian unas manifestaciones excepcionales. A grandes rasgos, son expresiones de diferentes etapas y horizontes, en las que se aprecian tipologías heterogéneas y una riqueza material distintiva. Su disfrute representa un aspecto potencial para la llegada de visitantes hacia este lugar, por lo que simbolizan oportunidades para el entorno en el que se sitúan.

La valorización de este patrimonio supone, entre otras consideraciones, un beneficio importante para sectores como el cultural, educativo o económico. A este respecto, produce un impacto positivo en la economía de una población, ya que constituye una fuente de ingresos, la generación de puestos de trabajos cualificados o el consumo de unos servicios asociados. Además, en su proyección se aprecia un activo cultural y educativo, promoviendo la recuperación del legado material de los grupos humanos asentados en este área a lo largo de la historia, favoreciendo la comprensión del pasado, las costumbres y tradiciones de un lugar. En los mismos términos, esta valorización debe plantearse desde la integración de aquellos valores que participan de una comunidad concreta y que participa del mismo espacio físico que estos bienes (Santos, 2007).

En estas páginas se ha tratado de presentar el ejemplo del Ayuntamiento de Daimiel, como institución que está apostando por una tutela eficaz, precisa y provechosa sobre su patrimonio. Para ello, se ha configurado un modelo de gestión que tiene en cuenta las características y peculiaridades de los vestigios comprendidos, dentro de un contexto territorial con ciertas particularidades. Este diseño debe resultar beneficioso tanto para los propios sitios comprendidos, como para toda la sociedad vinculada con los mismos. Asimismo, esta explotación debe realizarse dentro de una concepción racional, sostenible y respetuosa con estos conjuntos, premisas que deben prevalecer en todo momento en su planificación.

\footnotetext{
${ }^{4}$ A este respecto, una tradición local no demostrada estimaba su origen en el mundo romano. No obstante, las primeras referencias las encontramos a finales del siglo XIX, apareciendo ya en el Mapa Geográfico Nacional de 1888 (hoja 760).
} 
Entre las iniciativas desarrolladas podemos destacar las visitas organizadas al yacimiento arqueológico de la Motilla del Azuer, experiencia que ha permitido su visibilidad, tratando de optimizar aquellos aspectos que la singularizan. El número de personas que anualmente se acerca a este enclave está aumentando progresivamente, con una alta satisfacción sobre todos los servicios comprendidos. Esta relación no sólo es favorable para el propio recurso, sino que también origina un impacto positivo para el marco productivo de su espacio más próximo. Además, esta orientación divulgativa se está combinando con labores para su estudio, mantenimiento e interpretación.

En los mismos términos, podemos destacar la puesta en marcha desde la administración municipal del programa "Descubriendo Daimiel", continuidad del evento "Otoño por el Patrimonio". A través de estas campañas, iniciadas en el año 2018, se vienen celebrando diversas actividades como rutas senderistas, visitas a la arquitectura urbana de la localidad, exposiciones, programas con los centros educativos, etc., con la misión de dar a conocer el legado histórico de la ciudad, a la vez que conceder un protagonismo directo a la propia sociedad que, de una manera u otra, tiene una relación estrecha con el mismo.

En suma, la potencialización del patrimonio constituye un campo dinamizador con interesantes posibilidades para el impulso de un territorio, más si cabe en zonas con limitaciones desde el punto de vista económico, con una evidente falta de oportunidades labores o financieras. En este sentido, la gestión del patrimonio implica un valor añadido que puede suscitar el interés para personas, empresas y administraciones públicas, por lo que su inversión puede resultar muy beneficiosa para el desarrollo de una región concreta.

\section{Referencias}

Angulo, M. I. (2018). Conservación y restauración en el yacimiento arqueológico de la Motilla del Azuer, campañas 2015 y 2016. En IV Jornadas de Historia de Daimiel (pp. 31-44). Daimiel: Ayuntamiento de Daimiel.

Cejudo, D. (2013). Venta de Borondo: origen y evolución hasta nuestro días. En II Jornadas de Historia de Daimiel (pp. 71-84). Daimiel: Ayuntamiento de Daimiel.

Fernández-Infantes, M. (2013). Recuperación y conservación de las caleras tradicionales de Daimiel. En II Jornadas de Historia de Daimiel (pp. 317-329). Daimiel: Ayuntamiento de Daimiel.

Jérez, O. (2015). Arquitectura popular en el Parque Nacional de Las Tablas de Daimiel. Factores explicativos, tipología y cartografías. En III Jornadas de Historia de Daimiel (pp. 325-342). Daimiel: Ayuntamiento de Daimiel.

López-Menchero, V. M. (2010). Manual para la puesta en valor del patrimonio arqueológico al aire libre. Gijón: Ediciones Trea.

Martínez, L. (2011). Cultura y patrimonio en Castilla-La Mancha. Her\&Mus, 6, vol. II (4), 8-12.

Nájera, T., y Molina, F. (2004). Las motillas: un modelo de asentamiento con fortificación central en la Llanura Manchega. En R. García Huerta y J. Morales (Coords.), La Península Ibérica en el II mil. a.C.: poblados y fortificaciones (pp. 173-214). Cuenca: Ediciones de la Universidad de Castilla-La Mancha.

Nájera, T., Jiménez, S. A., Molina, F., Delgado, A., y Laffranchi, Z. (2012). La aplicación de los métodos de la antropología física a un yacimiento arqueológico: la Motilla del Azuer. Cuadernos de prehistoria y arqueología de la Universidad de Granada, (22), 149-182.

Santos Santos, J. F. (2007). La puesta en valor del patrimonio cultural y natural como recurso para el desarrollo en áreas rurales. Nuevas perspectivas, nuevas formas de gestión. En M. Zarzalejos y M. A. García Valero (Eds.), I Congreso de Patrimonio Histórico de Catilla-La Mancha, La gestión del patrimonio histórico regional, Tomo II, (pp. 189-200). Valdepeñas: UNED.

Torres Mas, M. (2015). La Motilla del Azuer: un yacimiento arqueológico de interés cultural en Daimiel (Ciudad Real). En III Jornadas de Historia de Daimiel (pp. 15-30). Daimiel: Ayuntamiento de Daimiel. 